\title{
Propriedades antioxidantes em subproduto do pedúnculo de caju (Anacardium occidentale L.): efeito sobre a lipoperoxidação e o perfil de ácidos graxos poliinsaturados em ratos
}

\section{Priscila Regina Bolelli Broinizi ${ }^{1}$, Elma Regina Silva de Andrade-Wartha ${ }^{1}$, Ana Mara de Oliveira e Silva1, Rosângela Pavan Torres ${ }^{1}$, Henriette Monteiro Cordeiro Azeredo², Ricardo Elesbão Alves², Jorge Mancini-Filho ${ }^{1 *}$}

${ }^{2}$ Departamento de Alimentos e Nutrição e Experimental, Faculdade de Ciências Farmacêuticas , Universidade de São Paulo, ${ }^{2}$ Centro Nacional de Pesquisa de Agroindústria Tropical, Empresa Brasileira de Pesquisa Agropecuária EMBRAPA

*Correspondência:

J. Mancini Filho

Departamento de Alimentos e

Nutrição Experimental

Faculdade de Ciências Farmacêuticas Universidade de São Paulo

Av. Dr. Lineu Prestes, 580 Bloco 14 05508-900 - São Paulo - SP, Brasil

E-mail: jmancini@usp.br
O caju (Anacardium occidentale L.) apresenta substâncias fenólicas, as quais são atribuidas propriedades antioxidantes. Sendo assim, o presente trabalho objetivou verificar a capacidade antioxidante em subproduto, ou seja, no bagaço do pedúnculo do caju. O potencial antioxidante do extrato hidroalcoólico (EHAlc) do bagaço do pedúnculo de caju foi avaliado em sistema de varredura do radical 2,2'-difenil-1-picrilhidrazilo (DPPH•) e em ensaio in vivo. No sistema DPPH, o extrato demonstrou atividade antioxidante de cerca de $95 \%$ em sua maior concentração $(1000 \mu \mathrm{g} / \mathrm{mL})$. Para o estudo in vivo, foram utilizados ratos Wistar administrando oralmente EHAlc (200 e $400 \mathrm{mg} / \mathrm{kg}$ de peso corpóreo) por 30 dias e analisados os tecidos plasmático, hepático e cerebral. Não houve alterações na peroxidação lipídica no plasma e no figado dos animais tratados comparados ao grupo controle. Contudo, foi observada redução da lipoperoxidação no cérebro dos grupos tratados. Além do mais, neste tecido, os animais tratados apresentaram maior quantidade de ácidos graxos poliinsaturados (AGPI), destacando-se o ácido docosahexaenóico (DHA). Estes resultados indicam que o EHAlc contém antioxidantes naturais efetivos e que podem contribuir na redução da lipoperoxidação e preservação dos AGPICL no tecido cerebral de ratos, dando indícios da capacidade antioxidante do bagaço do pedúnculo de caju CCP-76.

\section{Unitermos \\ - Pedúnculo de caju/ propriedade \\ - Lipoperoxidação \\ - Ácidos graxos/ poliinsaturados/estudo experimental}

- Ácido docosahexaenóico

- Antioxidantes naturais

\section{INTRODUÇÃO}

O desequilíbrio entre moléculas oxidantes e antioxidantes resulta na indução de danos celulares pelos radicais livres e tem sido chamado de estresse oxidativo, podendo causar danos aos lipídios, proteínas, carboidratos, ácidos nucléicos e outras substâncias oxidáveis (Sies, 1993; Leite, 2003). Este desequilíbrio, por sua vez, está associado a muitos fenômenos fisiológicos, patológicos e a processos adversos como inflamação, envelhecimento, carcinogênese entre outros (Dean et al., 1997).

Nesse sentido, os antioxidantes destacam-se por pre- 
venir a formação e a ação das espécies reativas de oxigênio e nitrogênio que se associam ao dano oxidativo (Andrade-Wartha, 2007). Os antioxidantes, quer sejam naturais ou sintéticos, possuem elevada estabilidade oxidativa em função de sua estrutura molecular, e por isso desempenham papel fundamental na prevenção àoxidação de substâncias. Sendo assim, os antioxidantes podem ser definidos como qualquer substância que, presente em baixas concentrações, quando comparado a um substrato oxidável, retarda ou inibe a oxidação desse substrato (Aust et al., 2001; Handelman, 2001).

Uma das conseqüências mais estudadas do estresse oxidativo é a peroxidação lipídica, que constitui uma reação em cadeia nos ácidos graxos poliinsaturados das membranas celulares, alterando a permeabilidade, fluidez e integridade das mesmas (Goode et al., 1995; Stahl, 2000). Ao mesmo tempo, é importante lembrar que os lípides desempenham papel fundamental na alimentação, não só pelo fornecimento de energia, transporte das vitaminas lipossolúveis e por conferirem palatabilidade aos alimentos, mas também pela importância de fornecerem ao organismo os ácidos graxos essenciais ácidos $\alpha$-linolênico $(\omega-3)$ e linoléico $(\omega-6)$ (Viola, 1997).

Sabe-se que os ácidos graxos poliinsaturados de cadeia longa (AGPICL) devem estar disponíveis em quantidades adequadas na dieta da população, com destaque para a sua presença imprescindível durante a gestação e lactação, períodos em que há crescimento e desenvolvimento de vários tecidos e órgãos (Tinoco et al., 2007). Além disso, como redução dos fatores de risco para as doenças cardiovasculares alguns estudos têm associado os ácidos graxos ômega-3 à diminuição da adesividade plaquetária e a promoção de uma pequena redução na pressão arterial (Rique et al., 2002).

Em frente de ações fisiológicas e deletérias dos processos oxidativos, destacando-se a peroxidação lipídica ou lipoperoxidação, a existência de compostos que inibam a oxidação em concentrações específicas poderá auxiliar controlando os processos oxidativos em alimentos e organismos.

Cabe lembrar que a prevenção da oxidação pode ocorrer por fatores intrínsecos do próprio alimento, representados pela compartimentalização dos lípides, pela presença de vitaminas antioxidantes como as vitaminas $\mathrm{C}, \mathrm{E}$, pelos carotenóides, que são compostos pró-vitamina A e pela presença de outros compostos cujas atividades têm sido bem comprovadas nos últimos anos em frutas e outros vegetais como os compostos fenólicos, tais como: flavonóides, ácidos fenólicos e as antocianinas (ManciniFilho, 2006).

Tendo em vista a capacidade antioxidante de compostos bioativos presentes em frutas, particularmente no pedúnculo de caju, destacando-se o potencial antioxidante do extrato alcoólico do bagaço, um subproduto do pedúnculo, demonstrado em estudos anteriores (Broinizi et al., 2007), e visando o melhor aproveitamento deste fruto, o presente trabalho teve como objetivo avaliar a capacidade antioxidante do bagaço do pedúnculo de caju e seus efeitos sobre a lipoperoxidação e o perfil de ácidos graxos poliinsaturados em ratos.

\section{MATERIAL E MÉTODOS}

\section{Amostra e preparação do extrato hidroalcoólico (EHAlc)}

As amostras de pedúnculo de caju clone CCP-76 foram provenientes da Estação Experimental de Pacajus/ CE - EMBRAPA, as quais foram submetidas a um tratamento especial conforme protocolo elaborado pela EMBRAPA, descrito por Broinizi et al. (2007). Foi utilizado o bagaço do pedúnculo de caju liofilizado e acondicionado em freezer a $-20{ }^{\circ} \mathrm{C}$ para análises posteriores.

O EHAlc foi preparado de acordo com o método descrito por Krygier e Solsulski (1982) com algumas modificações. O bagaço do pedúnculo de caju foi, inicialmente, submetido à extração com éter etílico na proporção de 1:5 (g de amostra: $\mathrm{mL}$ de solvente) durante uma hora em agitador magnético (modelo RO15 power, IKA ${ }^{\circledR}$, Staufen, Alemanha) à temperatura ambiente e a solução foi filtrada a vácuo em funil de Büchner. O resíduo resultante foi novamente extraído com álcool etílico $(90 \%)$ na mesma proporção anterior, seguindo o mesmo procedimento, obtendo-se assim o EHAlc.

Para a administração aos animais, o EHAlc foi evaporado em evaporador rotativo (B525, Micronal) sob vácuo, a $30^{\circ} \mathrm{C}$, com a finalidade de extrair todo o resíduo de etanol, em seguida ressuspenso em água filtrada.

Todos os reagentes e solventes utilizados foram de grau analítico. Os padrões de ácidos graxos láurico, mirístico, palmítico, palmitoléico, margárico, heptadecenóico, esteárico, oléico, vacênico, linoléico, $\alpha$-linolênico, araquídico, eicosanóico, beênico e lignocérico e DPPH• (2,2-difenil-1-picrilhidrazil) foram obtidos da Sigma Chemical Co. (St. Louis, EUA).

\section{Atividade antioxidante em sistema de varredura de radicais livres $(\mathrm{DPPH} \bullet)$}

A atividade antioxidante do EHAlc foi avaliada pelo sistema modelo de varredura do radical DPPH segundo Blois (1958) e Brand-Willians (1995), que tem por base a redução do radical DPPH $\bullet$. O procedimento, bem como as modificações, foram realizados seguindo o método descrito em Broinizi et al. (2007). 


\section{Protocolo experimental in vivo}

\section{Animais}

Ratos machos (Rattus novergicus, v. albinus) da linhagem Wistar ( $173 \pm 11,1 \mathrm{~g}$ de peso corporal) foram usados para avaliação do potencial antioxidante in vivo. Os animais foram divididos em três grupos, (controle, G1 e G2) contendo oito animais em cada gaiola, foram alimentados com ração comercial e água ad libitum, à temperatura de $22 \pm 2{ }^{\circ} \mathrm{C}$, em ciclo claro/escuro de $12 \mathrm{~h}$ no biotério de criação e experimentação da FCF/IQ - USP e foram distribuídos em três grupos experimentais com 8 animais cada, um grupo controle e dois tratados oralmente com EHAlc.

\section{Tratamento}

Durante o período de trinta dias os ratos receberam por gavagem EHAlc, nas concentrações de 200 ou $400 \mathrm{mg} / \mathrm{kg}$ de peso do animal, segundo o grupo G1 e G2, respectivamente. Os animais controle receberam apenas água filtrada também por gavagem.

\section{Procedimento experimental}

A ingestão da dieta e o peso dos animais foram monitorados diariamente durante o período de 30 dias, e ao final do período experimental, os ratos foram anestesiados com mistura de cetamina ( $80 \mathrm{mg} / \mathrm{kg}$ de peso corpóreo) e xilazina $2 \%(10 \mathrm{mg} / \mathrm{kg}$ de peso, via intraperitoneal $) \mathrm{e}$, então, retirados plasma, cérebro e fígado para análises posteriores.

Foram preparados homogeneizados do fígado e cérebro para as análises subseqüentes. Os tecidos hepático e cerebral retirados foram pesados e homogeneizados com tampão fosfato de potássio $0,1 \mathrm{M} \mathrm{pH} 7,4$ (1:10 p/v) em homogeneizador Potter-Elvehje. O homogeneizado foi centrifugado a $1010 \mathrm{x}$ g, por 20 minutos, à temperatura de $4{ }^{\circ} \mathrm{C}$ e o sobrenadante separado para a medição da peroxidação lipídica.

Determinação da lipoperoxidação pela produção de substâncias reativas ao ácido tiobarbitúrico (TBARS)

A avaliação da peroxidação lipídica pela medida da concentração de TBARS foi realizada segundo método descrito por Winterbourn, Gutteridge e Halliwell (1985).

Foi tomado $0,3 \mathrm{~mL}$ dos homogeneizados de fígado ou cérebro e o volume completado para $0,5 \mathrm{~mL}$ com tampão fosfato de sódio $0,1 \mathrm{M} \mathrm{pH}$ 7,4. Em seguida, adicionou-se $0,5 \mathrm{~mL}$ de $\mathrm{HCl} 25 \%, 45 \mu \mathrm{L}$ de BHT etanólico $2 \%$ e $0,5 \mathrm{~mL}$ de TBA ( $1 \% \mathrm{p} / \mathrm{v}$ em NaOH 0,05 M). Posteriormente, a solução de reação foi agitada em Vortex por 10 minutos e colocada em banho fervente, seguido de resfriamento em banho de gelo. Foi adicionado $1,5 \mathrm{~mL}$ de n-butanol e centrifugado a $1500 \mathrm{x}$ g por 10 minutos a $4{ }^{\circ} \mathrm{C}$. Após a centrifugação, foi coletada a fase superior e analisada em espectrofotômetro a $532 \mathrm{~nm}$. Para a determinação no plasma tomou-se diretamente, sem diluição, $0,5 \mathrm{~mL}$, seguiu-se o mesmo protocolo descrito acima. As determinações foram realizadas em triplicata. Para os cálculos foi feita curva padrão com 1,1,3,3-tetrametoxipropano $\left(6 \times 10^{-6} \mathrm{~mol} / \mathrm{L}\right)$. Os resultados foram expressos em $\mu \mathrm{mol} \mathrm{de}$ equivalentes de $\mathrm{MDA} / \mathrm{mg}$ de proteína.

A determinação do conteúdo de proteínas foi realizada conforme o método de Bradford (1985). Foi feita curva padrão de proteína com solução padrão de albumina.

\section{Perfil lipídico do tecido cerebral}

Foi obtida a fração lipídica, correspondente aos lipídios totais do cérebro dos animais, segundo a metodologia descrita por Association of Official Analytical Chemistry (2002). Posteriormente, a amostra foi esterificada seguindo o método de Hartman e Lago (1973). As condições cromatográficas seguiram os procedimentos descritos por Moreira e Mancini-Filho (2003).

\section{- Frações Lipídicas}

Para extração dos lípides totais, em triplicata, foram pesados $150 \mathrm{mg}$ da amostra de cérebro, em tubos acrescidos de $12,5 \mathrm{mg}$ de ácido pirogálico, $0,5 \mathrm{~mL}$ de etanol e $2,5 \mathrm{~mL}$ de $\mathrm{HCl} 8,3 \mathrm{M}$ e incubados a $70-80{ }^{\circ} \mathrm{C}$, sob agitação moderada, por 40 minutos, agitados em vortex a cada 10 minutos. Ao final do tempo de incubação, aos tubos, em temperatura ambiente, foram adicionados $5 \mathrm{~mL}$ de éter etílico, agitados por 3 minutos e, posteriormente, adicionados $5 \mathrm{~mL}$ de éter e novamente submetidos à agitação por mais 3 minutos. O material obtido foi centrifugado por 10 minutos a $6000 \mathrm{rpm}$ e os sobrenadantes extraídos, transferidos para novos tubos e acrescidos de $0,5 \mathrm{~mL}$ de padrão interno (éster metílico de ácido heptadecanóico, Sigma) e, por fim, evaporados com gás $\mathrm{N}_{2}$.

\section{- Obtenção dos ésteres metílicos de ácidos graxos}

A esterificação foi feita adicionando-se $2 \mathrm{~mL}$ de $\mathrm{NaOH}$ metanólico 0,5 M às frações lipídicas (descritas anteriormente) e aquecidos em banho-maria fervente por 5 minutos. Após a diminuição da temperatura a aproximadamente $40{ }^{\circ} \mathrm{C}$, foram adicionados $6 \mathrm{~mL}$ de mistura de esterificação e novamente, aquecidos em banho-maria fervente por 3 minutos. A seguir, foram acrescidos $5 \mathrm{~mL}$ de solução saturada de $\mathrm{NaCl}$, agitados em agitador tipo Vortex durante 1 minuto e realizada extração com $2 \mathrm{~mL}$ de hexano, transferindo a fase superior para outro tubo e adicionando $1 \mathrm{~mL}$ de solução saturada de $\mathrm{NaCl}$ com breve agitação. 
Novamente, a fase superior foi transferida para outro tubo e evaporada com nitrogênio gasoso. Por fim, os ésteres metílicos de ácidos graxos das amostras foram ressuspensos em $0,5 \mathrm{~mL}$ de hexano e acondicionados em freezer até o momento da análise cromatográfica.

\section{- Análise por cromatografia a gás}

As determinações cromatográficas foram realizadas em cromatógrafo a gás (modelo GC 17 A, Shimadzu, Kyoto, Japão), equipado com detector de ionização de chama. A coluna utilizada foi de sílica fundida SUPELCOWAX 10 (polietilenoglicol $30 \mathrm{~m}$ x 0,25 mm x 0,25 $\mu$ ) e o hélio foi usado como gás de arraste. A programação da temperatura se deu da seguinte forma: temperatura inicial, $170^{\circ} \mathrm{C}$, aumento para $225^{\circ} \mathrm{C}$, a $1{ }^{\circ} \mathrm{C} / \mathrm{min}$., mantida por 10 minutos As temperaturas do vaporizador e detector foram de 250 e $270{ }^{\circ} \mathrm{C}$, respectivamente. Os cromatogramas foram registrados em software Class GC e as áreas dos picos por um integrador GC Wortkstation Class-GC-10 (Shimadzu).

\section{Análise Estatística}

Todas as determinações foram efetuadas em triplicata, o tratamento estatístico dos dados se deu pela análise de variância (ANOVA) seguido do Teste de Tukey, através do software Prisma 3.0 (GraphPad). Os dados foram expressos como média \pm desvio padrão. $O$ valor de $p<0,05$ foi considerado, estatisticamente, significativo.

\section{RESULTADOS E DISCUSSÃO}

\section{Atividade antioxidante do EHAlc em sistema de varredura de radical DPPH•}

A avaliação da atividade antioxidante in vitro do EHAlc, a partir do bagaço de pedúnculo de caju, foi realizada em sistema de varredura do radical DPPH• e expressa em percentual de inibição. O EHAlc apresentou efetiva atividade de varredura do radical, principalmente na maior concentração $(1000 \mu \mathrm{g} / \mathrm{mL})$, com percentual em torno de $95 \%$, como mostra a Tabela I. É provável que esta atividade efetiva de seqüestro de radicais livres esteja correlacionada à quantidade elevada de compostos fenólicos, bem como os ácidos fenólicos com atividade antioxidante presentes no bagaço de pedúnculo de caju CCP-76 já quantificados e identificados por AndradeWartha (2007) e Broinizi et al. (2007).

Mahattanatawee et al. (2006) verificaram correlação positiva $(r=0,96)$ entre a atividade antioxidante em sistema DPPH e o teor elevado de compostos fenólicos totais de goiaba vermelha e carambola, sugerindo que estas substâncias, provavelmente, sejam contribuintes significativos na capacidade antioxidante em extratos de frutas.

Além disso, nossos resultados são condizentes aos já discutidos por Broinizi et al. (2007) que verificaram $88 \mathrm{e}$ $95 \%$ de atividade de varredura do radical $\mathrm{DPPH} \cdot$ numa concentração de $0,5 \mathrm{mg}$ de extrato aquoso e alcoólico, respectivamente, do bagaço de pedúnculo de caju CCP-76, e aos encontrados por Andrade-Wartha (2007) com 94\% de atividade de varredura do radical $\mathrm{DPPH} \bullet$ na concentração de 0,4 mg de extrato alcoólico do pedúnculo de caju CCP-76 sem o tratamento prévio da EMBRAPA.

Com base nesses dados, evidencia-se que os compostos bioativos presentes no extrato hidroalcoólico podem ter agido como seqüestradores de radicais pela capacidade de atuar como doador de hidrogênio (Shahidi et al., 2007).

\section{Ensaio experimental in vivo}

O efeito antioxidante do EHAlc do pedúnculo de caju na proteção contra os radicais livres foi verificado no organismo animal.

Dentro da perspectiva de proteger o organismo animal do processo oxidativo, os organismos utilizam sistemas de reparo e defesa contra os processos oxidativos, contudo, estes mecanismos com freqüência são inadequados a uma prevenção total e esse dano é acarretado pela formação de radicais livres.

Influência da suplementação do EHAlc no consumo e ganho de peso dos animais

O consumo de ração entre os animais, durante os 30 dias de tratamento, foi semelhante, não havendo diferenças significativas entre os grupos $(\mathrm{p}>0,05)$. O grupo controle apresentou consumo de 24,32 $\pm 2 \mathrm{~g} / \mathrm{animal} / \mathrm{dia}$; o G1 de $24,46 \pm 2,3 \mathrm{~g} /$ animal/dia e o $\mathrm{G} 2$ de $23,87 \pm 1,8 \mathrm{~g} /$ animal/dia. Sendo assim, evidencia que a administração do EHAlc não in-

TABELA I - Atividade antioxidante do extrato hidroalcoólico (EHAlc) do bagaço do pedúnculo de caju CCP-76

\begin{tabular}{lcccc}
\hline \multicolumn{4}{l}{ Capacidade antioxidante do EHAl em sistema de varredura do radical DPPH (\%)* } \\
\hline $62,5 \mu \mathrm{g} / \mathrm{mL}$ & $125 \mu \mathrm{g} / \mathrm{mL}$ & $250 \mu \mathrm{g} / \mathrm{mL}$ & $500 \mu \mathrm{g} / \mathrm{mL}$ & $1000 \mu \mathrm{g} / \mathrm{mL}$ \\
$18,57 \pm 0,011$ & $38,67 \pm 0,004$ & $67,67 \pm 0,003$ & $92,51 \pm 0,005$ & $95,26 \pm 0,001$ \\
\hline
\end{tabular}

*Os resultados estão expressos como média \pm desvio-padrão. 
fluenciou na ingestão de ração dos animais. Tal qual o consumo, não houve diferença estatisticamente significativa $(\mathrm{p}>$ $0,05)$ na média de ganho de peso dos animais que exibiram valores de 121,93 $\mathrm{g} \pm$ 9,25, 121,92 $\mathrm{g} \pm 13,42$ e 115,89 $\mathrm{g} \pm$ 11,17, para o grupo controle, G1 e G2, respectivamente.

A curva de crescimento dos animais pode ser vista na Figura 1, em que verifica-se que o crescimento dos animais foi constante e não diferiu entre os grupos $(p>0,05)$.

Esses resultados dão indícios de que os compostos presentes no bagaço do pedúnculo de caju não interferem no aproveitamento dos nutrientes da ração e demonstram que a administração do EHAlc, permitiu o desenvolvimento e o crescimento normais dos animais, excluindo a possibilidade de efeito antinutricional do extrato.

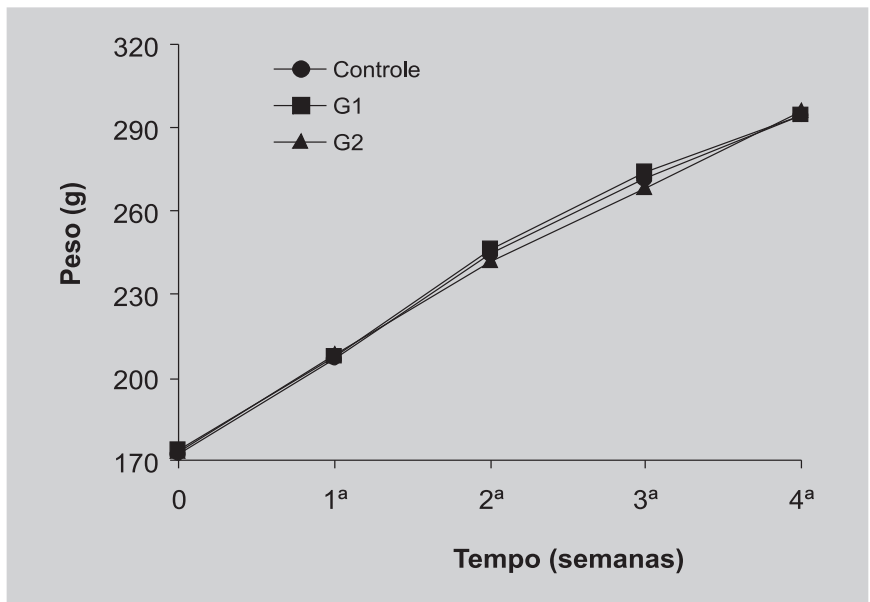

FIGURA 1 - Curva de crescimento de ratos submetidos à administração oral do extrato hidroalcoólico obtido a partir do bagaço do pedúnculo de caju CCP-76 tratado. Grupos: Controle (água filtrada); G1 (200 mg/kg de peso animal) e $\mathrm{G} 2$ (400 $\mathrm{mg} / \mathrm{kg}$ de peso animal).

\section{Determinação da lipoperoxidação pela produção de TBARS nos tecidos plasmático, cerebral e hepático.}

O índice de estresse oxidativo causado normalmente pelos radicais livres no organismo foi determinado pela peroxidação lipídica, que é considerada marcador importante do estresse oxidativo e, também, um dos principais fatores envolvidos no dano celular, causado por estes radicais (Balu et al., 2005).

De acordo com a análise do tecido plasmático e hepático, os resultados da lipoperoxidação se mantiveram nos mesmos níveis para todos os grupos, sem diferença significativa $(p>0,05)$, como podemos observar nas Figuras 2 e 3 , respectivamente.

É importante salientar que as substâncias produzidas pela peroxidação são instáveis e existe ausência de níveis

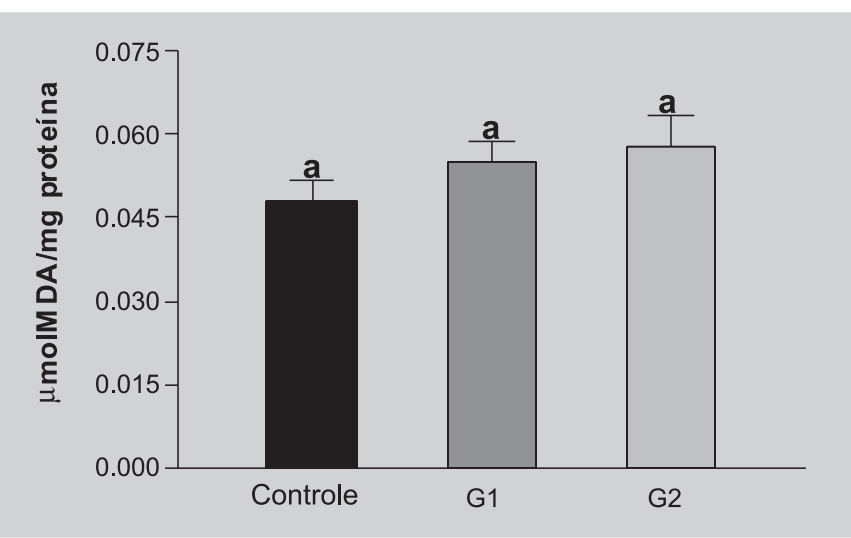

FIGURA 2 - Produção de substâncias reativas ao ácido tiobarbitúrico (TBARS) em tecido plasmático do controle, G1 e G2. Grupos: Controle (água filtrada); G1 (200 mg/kg de peso animal) e G2 (400 mg/kg de peso animal), p >0,05.

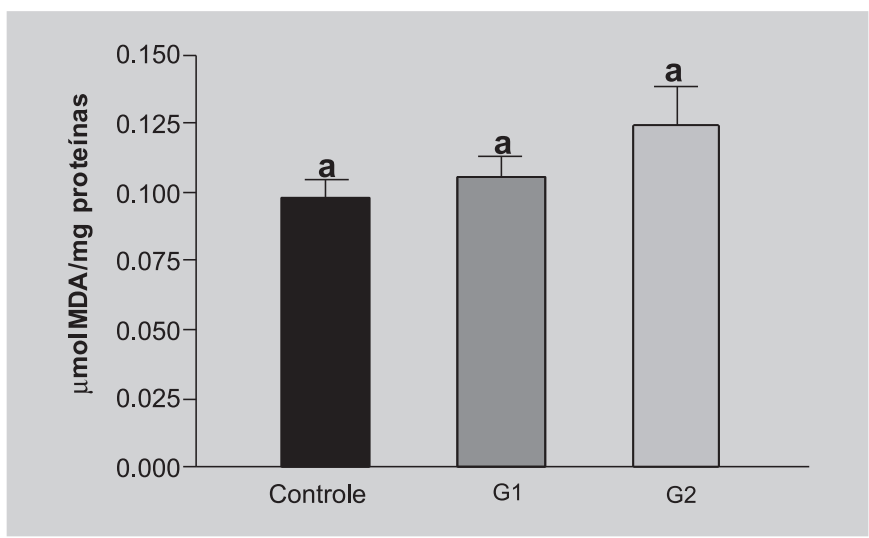

FIGURA 3 - Produção de substâncias reativas ao ácido tiobarbitúrico (TBARS) em tecido hepático do controle, G1 e G2. Grupos: Controle (água filtrada); G1 (200 mg/kg de peso animal) e G2 (400 mg/kg de peso animal), p > 0,05.

detectáveis em alguns fluidos e tecidos (Jackson, 1999).

O valor da inibição de TBARS, no tecido cerebral, de $82 \%$ encontrado no presente estudo, como mostra a Figura 4 , caracteriza diminuição significativa $(\mathrm{p}<0,05)$ no índice de peroxidação, resultado que se assemelha ao encontrado por Lima et al. (2006), com 84\% de inibição máxima da formação de malonaldeído (MDA) no cérebro de ratos, quando avaliada a peroxidação lipídica após administração de extrato hidroalcoólico de folhas de bardana.

Quando avaliada a inibição da oxidação lipídica no cérebro de rato, Andrade-Wartha (2007) constatou que o extrato aquoso do pedúnculo de caju CCP-76 foi efetivo, representando cerca de $40 \%$ de proteção a oxidação em sua maior dose $(240 \mathrm{mg} / \mathrm{kg}$ por via oral), caracterizando proteção à peroxidação lipídica.

Em recente estudo, Veigas et al. (2007), avaliando a 


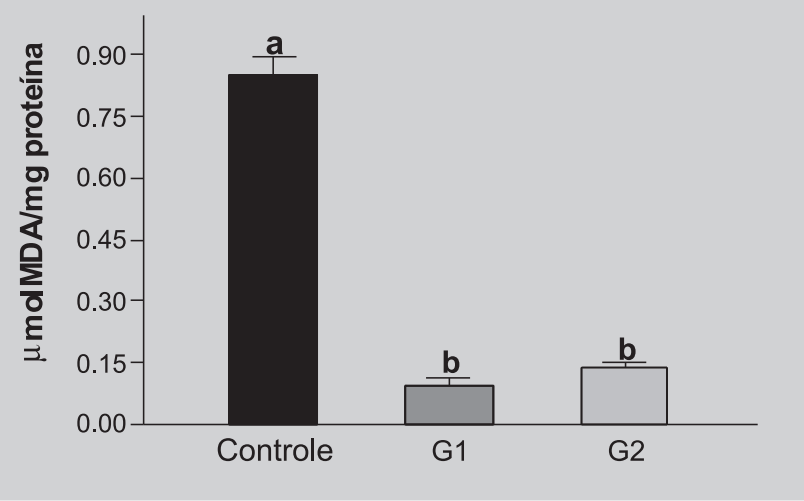

FIGURA 4 - Produção de substâncias reativas ao ácido tiobarbitúrico (TBARS) em tecido cerebral do controle, G1 e G2. Grupos: Controle (água filtrada); G1 (200 mg/kg de peso animal) e G2 (400 mg/kg de peso animal), p < 0,05.

atividade antioxidante das antocianinas provenientes da casca de jambolão, demonstraram inibição dos peróxidos lipídicos no tecido cerebral de ratos, na ordem de $94 \%$ na concentração de 5 ppm.

Da mesma forma, Naderi et al.(2004) observaram que após administração de 50mg do suco e de diferentes extratos de amora (Morus nigra), ocorreu baixa formação de MDA nos hepatócitos estudados.

Esses resultados sugerem possível ação protetora dos antioxidantes presentes no EHAlc do bagaço do pedúnculo de caju, demonstrando que a ingestão de compostos fenólicos pode propiciar inibição da oxidação lipídica, reduzindo o acúmulo tecidual de peróxidos lipídicos.

\section{Perfil de ácidos graxos do tecido cerebral}

O perfil lipídico foi determinado apenas no tecido cerebral, uma vez que somente neste tecido houve decréscimo significativo na produção de TBARS.

De acordo com Tinoco et al. (2007) os lipídios do cérebro são ricos em AGPICL $\omega-3$ e $\omega-6$, que desempenham papel fundamental no crescimento neuronal, tradução de sinais e excitabilidade das membranas neurais, além de atuarem na expressão de genes que regulam a diferenciação celular e o crescimento. Portanto, devido ao seu elevado teor de ácidos graxos poliinsaturados, o cérebro é especialmente susceptível à oxidação pelos radicais livres, além de possuir capacidade antioxidante relativamente baixa e elevado consumo de oxigênio (Vasconcellos et al., 1999).

No presente estudo, foram encontrados os seguintes ácidos graxos no tecido cerebral: tridecanóico, mirístico, palmítico, palmitoléico, margárico, esteárico, oléico, linoléico, araquídico, eicosenóico, eicosadienóico, eicosatrienóico, eicosatetraenóico, bêenico, docosaenóico, lignocérico, docosahexaenóico (DHA) e o tetracosenóico. Estes ácidos graxos foram distribuídos em saturados, monoinsaturados e poliinsaturados conforme apresentados na Tabela II.

Pode-se identificar que as quantidades de ácidos graxos saturados e monoinsaturados dos grupos tratados se mantiveram praticamente constantes quando comparadas ao grupo controle. Houve diferença significativa, nos grupos tratados, apenas com relação às quantidades de ácidos graxos poliinsaturados $(\mathrm{p}<0,05)$ e, em especial, com relação ao ácido DHA.

Dentre os ácidos graxos poliinsaturados com atividade biológica específica destacam-se o ácido $\alpha$-linolênico $(\omega$-3) e o ácido linoléico ( $\omega-6)$, e os dentre os ácidos graxos poliinsaturados de cadeia longa (AGPICL): dihomo- $\omega$ linolênico (20:3; $\omega$-6), araquidônico (20:4; $\omega$-6-AA), eicosapentaenóico (20:5; $\omega$-3 - EPA) e ácido docosahexaenóico (22:6; $\omega$-3 -DHA) (Simopoulos, 1996).

Os AGPI têm sido tradicionalmente considerados como moléculas bastante suscetíveis a situações de estresse oxidativo, devido à presença das duplas ligações e aos carbonos metilênicos (Huang, Wang, 2004; Henry et al., 2002). Os resultados deste estudo corroboram os encontrados na análise da lipoperoxidação do tecido cerebral no sentido de que o EHAlc exerceu uma ação protetora contra a oxidação dos ácidos graxos poliinsaturados no tecido cerebral, em particular ao DHA.

Segundo Tinoco et al. (2007) aproximadamente 10\% do peso do cérebro e $50 \%$ do peso seco são formados por lipídios, sendo metade constituído por fosfolipídios que compõem a massa cinzenta do cérebro e contêm grandes proporções de DHA e AA. Por isso, destacamos o percentual do ácido graxo DHA, Figura 5, por tratar-se de um ácido graxo importante para o sistema nervoso central como sugere esse mesmo estudo, realizado em humanos, cujas altas concentrações de DHA na retina, e de DHA e AA, na massa cinzenta do cérebro, indicam que estes ácidos graxos têm importante função no processo visual e neural.

De acordo com Das (2003), uma das funções dos AGPICL no cérebro, pode ser ainda a manutenção de adequado número de receptores de insulina nas membranas celulares neuronais, conseqüentemente modulando a função cognitiva. Além disso, vários autores têm proposto a necessidade de AGPICL para a evolução intelectual humana (Haag, 2003).

Pelo exposto, o efeito não é dose-dependente, tanto na avaliação da capacidade antioxidante quanto no perfil de DHA.

\section{CONCLUSÕES}

Os resultados obtidos neste trabalho revelam que o EHAlc do bagaço do pedúnculo de caju apresenta atividade 
TABELA II - Perfil de ácidos graxos no cérebro de animais tratados com extrato hidroalcóolico (EHAlc) do bagaço de pedúnculo de caju CCP-76 num período de 30 dias

\begin{tabular}{|c|c|c|c|c|}
\hline \multirow[t]{2}{*}{ Ácido graxo } & & \multicolumn{3}{|c|}{$\begin{array}{l}\text { Distribuição \% } \\
\text { Grupos }\end{array}$} \\
\hline & & Controle & G1 & $G 2$ \\
\hline Tridecanóico & $\mathrm{C} 13: 0$ & $0,42 \pm 0,32 *$ & $0,47 \pm 0,07$ & $0,34 \pm 0,06$ \\
\hline Mirístico & $\mathrm{C} 14: 0$ & $0,20 \pm 0,10$ & $0,2 \pm 0,02$ & $0,22 \pm 0,10$ \\
\hline Palmítico & $\mathrm{C} 16: 0$ & $19,95 \pm 0,93$ & $20,59 \pm 1,38$ & $20,29 \pm 1,79$ \\
\hline Palmitoléico & C16:1 & $0,41 \pm 0,08$ & $0,54 \pm 0,11$ & $0,47 \pm 0,06$ \\
\hline Margárico & $\mathrm{C} 17: 0$ & $0,28 \pm 0,05$ & $0,26 \pm 0,02$ & $0,27 \pm 0,02$ \\
\hline Esteárico & C18:0 & $25,52 \pm 2,92$ & $23,43 \pm 0,83$ & $23,34 \pm 2,02$ \\
\hline Oléico & C18:1 & $22,81 \pm 1,34$ & $22,43 \pm 1,48$ & $22,85 \pm 2,11$ \\
\hline Linoléico & C18:2 & $0,77 \pm 0,17$ & $0,80 \pm 0,08$ & $0,80 \pm 0,13$ \\
\hline Araquídico & $\mathrm{C} 20$ & $0,80 \pm 0,34$ & $0,77 \pm 0,17$ & $0,88 \pm 0,21$ \\
\hline Eicosenóico & C20:1 & $1,94 \pm 0,82$ & $1,79 \pm 0,61$ & $2,31 \pm 0,87$ \\
\hline Eicosadienóico & C20:2 & $0,2 \pm 0,14$ & $0,15 \pm 0,06$ & $0,22 \pm 0,12$ \\
\hline Eicosatrienóico & $C 20: 3 n-6$ & $9,13 \pm 3,7$ & $0,39 \pm 0,05$ & $0,45 \pm 0,09$ \\
\hline Eicosatetraenóico & C20:4 & $1,55 \pm 3,37$ & $11,84 \pm 0,71$ & $10,79 \pm 1,17$ \\
\hline Bêenico & $\mathrm{C}: 22$ & $0,89 \pm 0,20$ & $0,71 \pm 0,19$ & $0,88 \pm 0,25$ \\
\hline Docosaenóico & $\mathrm{C} 22: 1$ & $0,25 \pm 0,07$ & $0,22 \pm 0,07$ & $0,28 \pm 0,10$ \\
\hline Lignocérico & $\mathrm{C} 24: 0$ & $1,92 \pm 0,34$ & $1,58 \pm 0,33$ & $1,71 \pm 0,40$ \\
\hline Docosahexaenóico DHA & $\mathrm{C} 22: 6$ & $10,71 \pm 1,01^{\mathrm{a}}$ & $12,03 \pm 0,78^{b}$ & $12,06 \pm 0,73^{b}$ \\
\hline Tetracosenóico & $\mathrm{C} 24: 1$ & $2,16 \pm 0,44$ & $1,8 \pm 0,52$ & $1,80 \pm 0,60$ \\
\hline \multirow[t]{3}{*}{ Total } & Saturados & $49,99 \pm 3,2^{\mathrm{a}}$ & $48,02 \pm 1,67^{a}$ & $47,93 \pm 3,00^{a}$ \\
\hline & Monoinsaturados & $27,58 \pm 2,49^{a}$ & $26,77 \pm 2,52^{\mathrm{a}}$ & $24,32 \pm 1,41^{\mathrm{a}}$ \\
\hline & Poliinsaturados & $22,36 \pm 2,01^{a}$ & $25,21 \pm 1,27^{\mathrm{a}}$ & $27,71 \pm 3,55^{b}$ \\
\hline
\end{tabular}

$\dagger$ Grupos: controle (água filtrada); G1 (200 mg/kg de peso animal) e G2 (400 mg/kg de peso animal).

* Média e \pm desvio padrão, $\mathrm{p}<0,05$.

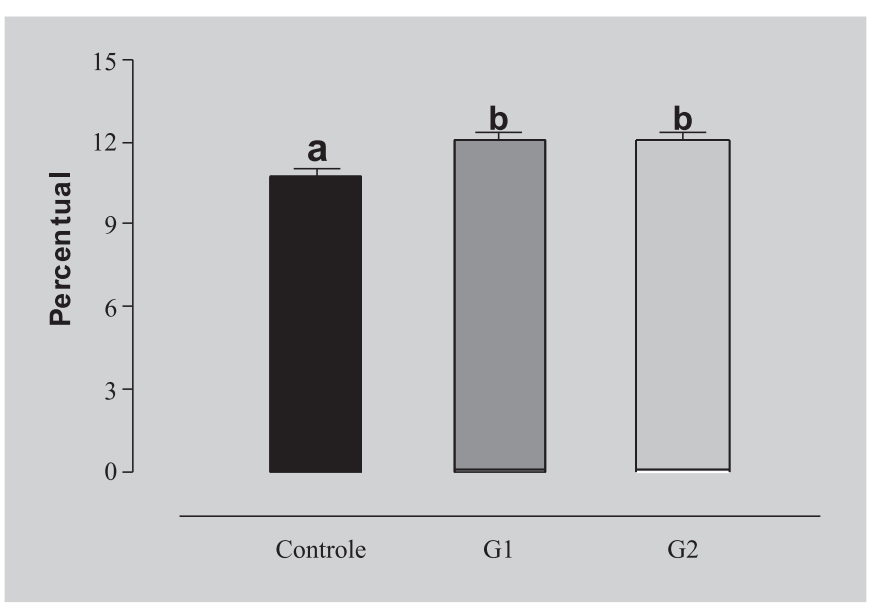

FIGURA 5 - Percentual do ácido graxo DHA no cérebro dos animais controle e tratados com extrato hidroalcoólico (G1 $100 \mathrm{mg} / \mathrm{kg}$ de peso; G2 $200 \mathrm{mg} / \mathrm{kg}$ de peso animal), $\mathrm{p}<0,05$. antioxidante in vitro pelo seqüestro do radical DPPH e in vivo pela diminuição do nível de peroxidação no tecido cerebral, observada também pela preservação do DHA, ácido graxo de grande susceptibilidade frente à oxidação, nos animais que receberam o extrato do bagaço do pedúnculo de caju. Isso indica a possibilidade da realização de mais estudos, visando à utilização deste material considerado descarte na obtenção da castanha de caju.

\section{ABSTRACT}

\section{Antioxidant properties in cashew apple byproduct (Anacardium occidentale L.): effect on lipoperoxidation and on the polyunsaturated fatty acids profile in rats}

The cashew apple (Anacardium occidentale L.) contains phenolic compounds usually related with antioxidant 
properties. Then, the aim of this study was to investigate its antioxidant capacity. The antioxidant capacity of the hydroalcoholic extract of the cashew apple pulp (EHAlc.) was assessed for the scavenging of the 2,2-diphenyl-1picrylhydrazyl radical (DPPH) by in vitro method and by an in vivo essay. For this essay a 30-day oral (gavage, EHAlc. 200 and $400 \mathrm{mg} / \mathrm{kg}$ ) study was conducted in Wistar male rats, evaluating hepatic, plasma and brain tissues. In DPPH model, the extract demonstrated antioxidant activity of $95 \%$ (largest concentration, $1000 \mu \mathrm{g} / \mathrm{mL}$ ). There were found no relevant peroxidation comparing the treated animals with the control group. However, the treated group presented a lower level of brain lipoperoxidation. Also in the treated animals brain tissue was found the largest amount of polyunsaturated fatty acids (PUFA), mainly docosahexaenoic (DHA). Therefore, the analyzed extract from cashew apple pulp clone CCP-76 contains effective natural antioxidants, responsible for free radical scavenging in vitro and also for decreasing the brain lipoperoxidation and keeping the PUFAS levels in Wistar rats.

UNITERMS: Cashew apple/propeties. Lipoperoxidation. Fatty acids/polyunsaturated/experimental study. Docosahexaenoic acid. Natural antioxidants.

\section{AGRADECIMENTOS}

Os autores agradecem à EMBRAPA, ao CNPq e à FAPESP pelo suporte financeiro.

\section{REFERÊNCIAS BIBLIOGRÁFICAS}

AUST, O.; SIES, H.; STAHL, W.; POLIDORI, M.C. Analysis of lipophilic antioxidants in human serum and tissues: tocopherols and carotenoids. J. Chromatogr, v.936, n.1, p.83-93, 2001.

ANDRADE-WARTHA, E.R.S. Capacidade antioxidante in vitro do pedúnculo de caju (Anacardium Occidentale L.) e efeito sobre as enzimas participantes do sistema antioxidante de defesa do organismo animal. São Paulo, 2007. 111p. [Tese de Doutorado. Faculdade de Ciências Farmacêuticas. Universidade de São Paulo].

ASSOCIATION OF OFFICIAL ANALYTICAL CHEMISTRY. Official methods of analysis of AOAC international. 17 ed. Arlington: AOAC, 2002. cap.41, p.20-24A.[Official Method n.996.06 - Fat (total, saturated and unsaturated) in food].
BALU, M.; SANGEETHA, P.; HARIPRIYA, D.; PANNEERSELVAM, C. Rejuvenation of antioxidant system in central nervous system of aged rats by grape seed extract. Neurosci. Lett., v.383, n.3, p.295-300, 2005.

BLOIS, M.S. Antioxidant determinations by the use of a stable free radical. Nature, v.181, n.4617 p.1199-1200, 1958.

BRAND-WILLIANS, W.; CUVELIER, M.E., BREST, C. Use of free radical method evaluate antioxidant activity. Lebensm.-Wiss. Technol., v.28, n.1, p.25-30, 1995.

BROINIZI, P.R.B.; ANDRADE-WARTHA, E.R.S.; SILVA, A.M.O.; NOVOA, A.J.V.; TORRES, R.P.; AZEREDO, H.M.C.; ALVES, R.E.; MANCINI-FILHO, J. Avaliação da atividade antioxidante dos compostos fenólicos naturalmente presentes em subprodutos do pseudofruto de caju (Anacardium occidentale L.). Ciênc. Tecnol. Aliment., v.27, n.4, p.902-908, 2007.

DAS, U.N. Long-chain polyunsaturated fatty acids in the growth and development of the brain and memory. Nutrition, v.19, n.1, p.62-65, 2003.

DEAN, R.T.; FU, S.; STOCKER, R.; DAVIES, M.J. Biochemistry and pathology of radical-mediated protein oxidation. Biochem. J., v.324, n.1, p.1-18, 1997.

HAAG, M. Essential fatty acids and the brain. Can. J. Psychiatry, v.48, n.3, p.195-203, 2003.

HANDELMAN, G.J. The evolving role of carotenoids in human biochemistry. Nutrition, v.17, n.10, p.818-822, 2001 .

HARTMAN, L.; LAGO, R.C.A. Rapid preparation of fatty acid methyl esters from lipids. Lab. Pract., v.22, n.6, p.475-476, 1973.

HENRY, G.E.; MOMIN, R.A.; NAIR, M.G.; DEWITT, D.L. Antioxidant and Cyclooxygenase activities of fatty acids found in food. J. Agric. Food Chem., v.50, n.8, p.22312234, 2002.

HUANG, L.H.; WANG, B.G. Antioxidant capacity and lipophilic content of seaweeds collected from the Qingdao coastline. J. Agric. Food Chem., v.52, n.16, p.4993-4997, 2004. 
JACKSON, M.J.An overview of methods for assessment of free radical activity on biology. Proc. Nutr. Soc., v.58, n.4, p.1001-1006, 1999.

KRYGIER, K.; SOSULSKI, F.; HOGGER, L. Free, sterified, and insoluble-bound phenolic acids. 1. Extraction and purification procedure. J. Agric. Food Chem., v.30, n.2, p.330-334, 1982.

LEITE, H.P.; SARNI, R.S. Radicais livres, antioxidantes e nutrição. Rev. Bras. Nutr. Clín., v.18, n.2, p.60-65, 2003.

LIMA, A.R.; BARBOSA, V.C.; SANTOS FILHO, P.R.; GOUVÊA, C.M.C.P. Avaliação in vitro da atividade antioxidante do extrato hidroalcóolico de folhas de bardana. Rev. Bras. Farmacogn., v.16, n.4, p.531-536, 2006.

MAHATTANATAWEE, K.; MANTHEY, J.A.; TALCOTT, S.T.; GOODNER, K.; BALDWIN, E.A. Total antioxidant activity and fiber content of select Floridagrown tropical fruits. J. Agric. Food Chem., v.54, n.19, p.7355-7363, 2006.

MANCINI-FILHO, J. In: COSTA, N.M.B., ROSA, C.O.B., eds. Alimentos funcionais. Viçosa: Folha de Viçosa, 2006. p.99-114.

MOREIRA, A.V.B.; MANCINI-FILHO, J. Atividade antioxidante das especiarias mostarda, canela e erva-doce em sistemas aquoso e lipídico. Nutrire, v.39, v.25, p.3146, 2003.

NADERI, A.G.; ASGARY, S.; SARRAF-ZADEGAN, N.; OROOJY, H.; AFSHIN-NIA, F. Antioxidant activity of three extracts of Morus nigra. Phytother. Res., v.18, n.5, p.365-369, 2004.

RIQUE, A.B.R.; SOARES, E.A.; MEIRELLES, C.M. Nutrição e exercício na prevenção e controle das doenças cardiovasculares. Rev. Bras. Med. Esporte, v.8, n.6, p.111, 2002.
SIES, H. Strategies of antioxidant defence: review. Eur. J. Biochem., v.215, n.2, p.213-219, 1993.

SIMOPOULOS, A.P. Omega-3 fatty acids. Part 1: Metabolic effects on omega-3 fatty acids and essenciatility. In: SPILLER, G.A., (Ed.). Handbook of lipids in human nutrition. $1^{\text {a }}$ ed. Roca Raton: CRC Press, 1996. 256 p.

SHAHIDI, F.; ALASALVAR, C.; LIYANA-PATHIRANA, C.M. Antioxidant phytochemicals in hazelnut kernel (Corylus avellana L.) and hazelnut byproducts. J. Agric. Food Chem., v.55, n.4, p.1212-20, 2007.

TINOCO, S.M.B.; SICHIERI, R.; MOURA, A.S.; SANTOS, F.S., do CARMO, M.G.T. Importância dos ácidos graxos essenciais e os efeitos dos ácidos graxos trans do leite materno para o desenvolvimento fetal e neonatal. Cad. Saúde Pública, v.23, n.3, p.525-534, 2007.

VASCONCELLOS,A.P.; MANOLLI, L.P.; SILVEIRA, P.P.; GAMARO, G.D.; TORRES, I.L.S.; DALMAZ, C. Effect of two different models of chronic stress on oxidative stress in cerebral cortex and hippocampus of rats. In: MEETING OF SOUTH AMERICAN GROUP FOR FREE RADICAL RESEARCH, 1, Florianópolis, 1999. Anais. Florianópolis: CCB/UFSC, 1999.

VEIGAS, J.M.; NARAYAN, M.S., LAXMAN, P.M., NEELWARNE, B. Chemical nature, stability and bioefficacies of anthocyanins from fruit peel of syzygium cumini Skeels. Food Chem., v.105, n.2, p.619-627, 2007.

VIOLA, P. Azeite de oliva e a saúde. Madrid: Conselho Oleícola Internacional, 1997. 64p.

Recebido para publicação em 10 de março de 2008 Aceito para publicação em 25 de junho de 2008 